\title{
Research on Color Aesthetic Synesthesia Driven by Adolescent Physical
}

\author{
Hui Zhu \\ Beijing Technology and Business University \\ Beijing, China \\ teacherzhui@126.com
}

\begin{abstract}
Based on theoretical knowledge of color science, youth development, aesthetics, etc, adolescent physical characteristics have been analyzed, and the color aesthetic synesthesia concept has been put forward. The process and characteristics of aesthetic synesthesia between color and sex driven by adolescent sexual have been focused on .At last it has been drawn that the sexual energy accumulation of adolescence can be released by the color aesthetic synesthesia behavior, and they can learn from the positive, healthy, aesthetic,and passion spiritual nourishment.
\end{abstract}

Keywords-Adolescent Physical ; Color Aesthetic; Color and Sexual Synesthesia

\section{INTRODUCTION}

Edison has said: "Any new and unusual things can cause a pleasure in the imagination, because this kind of thing make the mind a pleasant surprise, it can satisfy its curiosity, to make it to get a new idea that never have originally. This factor makes a monster also appears to be a charming magic, natural defects can also cause us pleasure, this factor requires that things should change ".[1]This can be the footnotes for we studying color aesthetic synesthesia driven by adolescent physical.

\section{A. Adolescent Physiological Characteristics}

Dramatic changes in adolescent physical are not only the external shape, volume changes, but also accompanied by internal conversion to a qualitative change, reaching sexual maturity. Physiological changes, especially the sexual maturity has the special effects of their psychological development. Adolescent physical development involves three aspects of change: changes in the external shape of the body, body function and nervous system development, sexual maturity, in which the sexual mature has great impact on adolescent cognitive development, personality development and social development.[2]

Young people gradually show interest in sexual knowledge due to sexual maturity. Boys and girls explore sexual knowledge through various media peep psychological description and appreciate nude art. In addition, with the awakening of sexual consciousness and development, they inevitably performance the love and the pursuit of the opposite sex. Accompanied by physiological and psychological phenomenon of sexual desire and sexual impulses, in the stimulation of the sexual impulses, in order to satisfy the sexual desires, young people often take compensatory and masturbation, by observing pornographic material and peep heterosexual body to meet the sexual impulses behaviors. Knowledge books, the screen in the film and television literature, description, and even a variety of colors, all can become the object of the sexual impulse through boys and girls psychological perspective and imagination. At this time the boys and girls were not married and have no sexual gratification, which cause tension and desire can not meet the " sexual hungry" feeling, and began to seek through a variety of ways to meet the sexual impulses of masturbation, including color aesthetic synesthesia behavior.

\section{B. Color Aesthetic Synesthesia}

Human perception include vision, hearing, touch, taste and smell. These feelings are caused by different sensory organs, and sent by different neural channels, but through scientific research, they can occur temporary connection in the nerve center. We call psychology synesthesia that is a feeling caused by another feeling.[3] Anything are in front of us ,the ear, nose, tongue, eyes and other organs will also be excited, and each give their best to find and capture the perception of hearing, smell, taste, vision, and the corresponding characteristics. Each sense organ through different channels of information transmit to the brain, and combine with saved experience in the brain to form a complete multi-dimensional impression.

Because color cause visual reflect, and it is inevitably more or less accompanied by a chain reaction of hearing, smell, touch, then the color aesthetic synaesthesia contains color listen, color shape, color flavor, color olfactory, color temperature, color sex.In Which color listen, color shape, color taste, color olfactory are common, and youth are the same as adult on these basic synesthesia. However, based on the physiological changes especially synesthesia behavior between color and sex in the sex drive ,have unique color aesthetic characteristics.

\section{COlOR SeXual Aesthetic Synesthesia}

Adolescence is a rapidly maturing period. Long-term accumulation of energy must be release through various 
channels, in which color sexual aesthetic synesthesia is one of the effective way. For example, women in pale emphasize the pornographic nature of the upper body (breasts, slender waist); purple skirt is dynamic hidden implying the existence of the legs and sex; skirt completely cover the lower body to excite the imagination of the boys. When girls occasionally lift the skirt, the invisible part of the faceless white feet and legs suddenly appear, this brief reveal is the strong sexual attraction. In fact, by the color of the cover can be said that both covered, but also to stimulate. Especially in bright light color of the female characteristics, often makes male juvenile reverie talk, girl hazy beauty, smooth, graceful, subtle, giving gentle with quite the feeling. (Fig. 1).

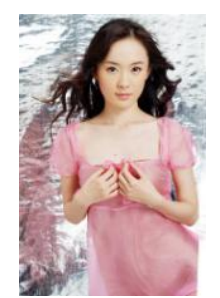

Fig. 1 Color Sexual Synesthesia

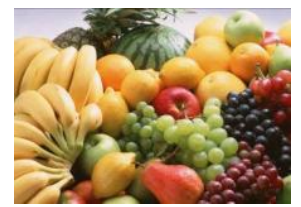

Fig. 2 Fruits and Vegetables

In another example, according to the Chicago smell, taste Research Foundation study, when the girls see the fruit color, they will smell the aroma in the mouth when chewing candy, if they see the fruits and vegetables color (Fig. 2 ), which make the girls clitoris blood flow increased by $13 \%$. When male youth see the purple, orange associate to imagine lavender and pumpkin pie taste, they will feel extra irritation.

Taste, is the most important feeling organ. Since we sucked mother milk we have developed oral sexual pleasure. The people first experience the oral phase, when see anything they first put it into the mouth, through tongue exploring the strange or the familiar world [4]. Kiss is wonderful because the structure of lips is different from the structure of the normal skin. Such skin organizations only be in clitoris, penis and lips, which have different skin surface color and texture. So when male juvenile are in sex germination period ,they see the girl rich, pink lips ,then they can not help but feel the girls body fragrance, thought imagination, it will be fascinating kiss and sexual pleasure (Fig. 3).

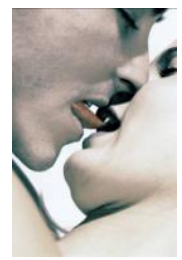

Fig. 3 Kiss

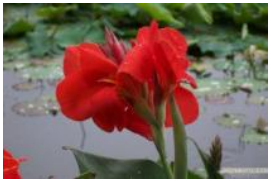

Fig. 4 Red Canna

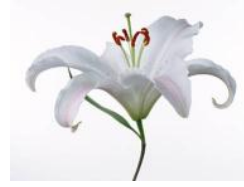

Fig. 5 Llily

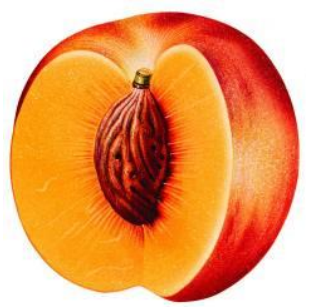

Fig. 6 Stone

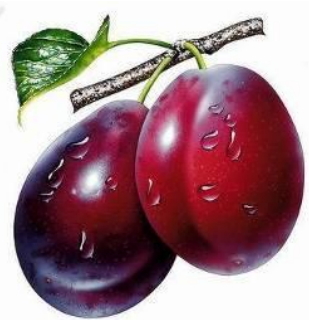

Fig. 7 Plums

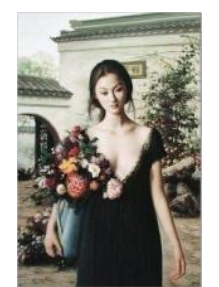

Fig. 8 Beautiful Girl 


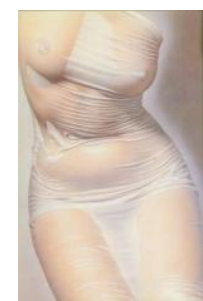

Fig. 9 Rain Girl

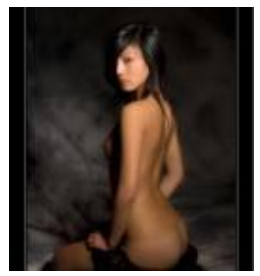

Fig. 10 Sexy girl

Another example is when the girls enjoy the bright red, dark red petals intertwined and prominent red canna, they can not help but think of the sacred, delicate and beautiful genitals, like the genitals and inner labia deep superimposed (Fig. 4). When male juvenile watch the lily, regardless of color or shape, they are interested in the center of flower which straightly erect between the flower (Fig. 5). [5] Hardness and softness, which just as if the intercourse of men and women.

All kinds of view of people fly free state of mind, enjoy sexy joy. For example, when we make apple half, the color and shape of the central stone part make they imagine the color and flavor in the depth of woman body (Fig. 6). Another example is some East men and women will see their own black or darker brown genitals as Chocolate, poured by a stream of black thick sweet gravy, and it has dark halo. Another example is the popular purple, purple little black plums (Fig. 7), open bite, and pulls out a dark red flesh, shed dark red juice, dark rich in several colors to incorporate the beauty of the female genitals color integration. In fact, the fruit skin, flesh color, full of water and juice, sweet flesh are similarity implicated with and the sexual organs have not let go of .Boys and girls often associate vermilion red of cherry, the red of the black pearl wax apples, wildfire red of mango, dark red of litchi, pink of peach, orange of papaya associate with labia, clitoris or glans penis and scrotum.

What color of beautiful girl is in boys eyes ? Firstly , cherry mouth, delicate pink run, soft and full, plush, slightly upturned mouth, with lips beautiful arc-shaped curve, with a full vigor, naughty, cause male teenager the instinctive desire. Secondly, the shiny black eyes hold tears .Speaking of hair, more attractive hair is an oriental show, black, smooth and straight shawl that naturally messy, fluttering in the wind, natural and free, and which make the boys distracted (Fig. 8).[6] Boys in adolescence most concern about girl's growing bulge in the chest. Through the clothes, especially when wearing light-colored shirt after rain, looming breast contour, boys imagine the girls exquisite, soft, milky white breasts, bright colors of pink, nipple and areola (Fig. 9). Graceful and slender waist curve of the girl determine the level of temptation in the boys minds. From the color, the boys prefer a little less bronze waist, because this color always gives them the youth and vigor, of course, a lot of boys like the color white and eclectic. Boys see the girls hips in addition to hip-shaped, and pay more attention to its color. Chinese boys like most of the white woman's body color, hip color may prefer the original, wild and some, such as bronze (Fig.10).

\section{CONCLUSION}

In life, association can make people get the freedom transcending time and space, then in color aesthetic, association is the basic conditions for young people aesthetic enjoyment . Association can make the color into vivid aesthetic image; it can make the color symbol to be understood; it makes empathy can be generated. Puberty, is the initial stages of sexual enlivened and germination, of course, it is spiritual realm unfusion with all specifications, admonition. The most active and the most blooming stage, naturally catch up with the most intense curiosity and desire to explore the spiritual world stage, happens to be the most active stage of fantasy, exaggeration, association psychology. At this stage, the feeling of thinking is jerky and it is difficult to incorporate into the thinking of a more mature system, but precisely the feeling of thinking, sensitive memory embrace a strong fresh color visual stimuli, to learn from the positive, healthy, aesthetic passion spiritual nourishment.

\section{ACKNOWLEDGEMENTS}

Beijing Philosophy and Social Science Planning Project (12SHB009)

\section{REFERENCES}

[1] The aesthetic Department of the Philosophy Department of Peking University. Western aestheticians Aesthetics and beauty [M], Beijing: The Commercial Press, 1980

[2] LI Bo. Contemporary youth aesthetic characteristics and attribution analysis [J] China Youth Research., 2009 (06)

[3] ZHANG Ling-hao. Integrated thinking of product color design [J]. Packaging Engineering, 2005(06)

[4] ZHANG Jing-qiong. Chinese and foreign clothing history glance [M] Shanghai: China Textile University Press, 2000

[5] ZHANG Xiao-mei. The woman's body in the eyes of man [M] Beijing: CITIC Publishing House, 2006

[6] ZHU Hui. Research on the color aesthetic mode based on adolescent emotional characteristics [J]. Packaging Engineering, 2013(02) 